\title{
Automated substantiation of multivariate land use planning projects
}

\author{
Olga Sorokina ${ }^{1 *}$, Ilya Fomkin ${ }^{1}$, Larisa Petrova $^{1}$, Elena Zatsepina ${ }^{1}$, and Ellina Mamedova ${ }^{1}$ \\ ${ }^{1}$ State University of Land Use Planning, Kazakova, 15, Moscow, 105064, Russia
}

\begin{abstract}
The intensification of the Russian economy determines the need for forecasting and planning agricultural production at the level of specific agricultural organizations and producers. In the context of an annually changing market, the most important factor in the innovative development of the agricultural sector is the system of land use planning measures. It creates the most favorable organizational and territorial prerequisites for agricultural production. The most optimal method of land use planning design is the multivariant method, which involves analyzing several options and selecting the best according to technical and economic indicators. It determines the need for improving the methodology for substantiating multivariate land use planning projects based on automated technologies. The above mentioned circumstances determined the goal of research, which is improving the Kolos software package. The approach involves clarifying the used regulatory and guidance information and updating the composition and relationships of software modules. An automated assessment of normative and actual indicators allows analyzing up to 10 options for organizing a crop rotation system and arranging their territory, choosing the optimal one and guaranteeing the rational use of each hectare of land that provides solutions to production, environmental and social problems. The considered software package ensures the high quality of land use planning decisions when planning and organizing the rational use of the country's land resources. This allows reducing the cost of design and use planning work, increasing their reliability and accessibility for agricultural organizations in all regions of the Russian Federation.
\end{abstract}

\section{Introduction}

The intensification of the market economy brings to the fore the forecasting and planning of agricultural production at the level of specific producers.

The effectiveness of agricultural organizations is determined by a timely response to the structure of global and domestic Russian supply and demand for agricultural products. The need for ensuring food security of the country and implementing the import-substituting policies affected by foreign sanctions require the development of "flexible" agricultural production $[1,2,3]$.

\footnotetext{
*Corresponding author: sorokinaoa81@gmail.com
} 
Researchers note that in the context of an annually changing market, the most important leverage for the innovative development of the agricultural sector is the system of land use planning measures that creates the most favorable organizational and territorial prerequisites for agricultural production and ensures the exclusion of land degradation $[4,5$, 6]. A special role is played by on-farm land management, which allows comparing annual financial plans for the development of farms with land resources. It also allows considering their productive and territorial properties as accurately as possible, such as soil fertility, terrain, location, configuration, transport factor, etc.

At the same time, the most optimal method of land use planning design is the multivariant method, which involves considering several options and selecting the best based on technical and economic indicators in the aggregate. In this regard, there is a need to improve the methodology for substantiating multivariate land use planning projects based on automated technologies.

Improving the automation of land use planning calculations will not only allow making a qualitative breakthrough in the information organization support of rational use of land resources owned by individual agricultural organizations, but also to improve the work technology that ensures the optimal use of each hectare of land [7, 8]. The considered software package will allow abandoning the implementation of routine workflows, eliminating the intermediate links of traditional technologies, reducing the amount of manual calculations, as well as increasing the informational value of output documents and minimizing the cost of developing land use planning projects.

The high quality of land use planning decisions, the reduction in the cost of design and use planning work will increase the degree of their accessibility for agricultural organizations in all regions of the Russian Federation.

\section{Materials and method}

In modern market conditions in agricultural organizations, such a crop rotation system that will contribute to the production of products with maximum economic efficiency and ensure the restoration of soil fertility is required to be designed. It should also consider other design elements of on-farm land use planning and the specifics of using agricultural territories. Moreover, the implementation of the crop rotation system should fit into the framework of limited time, labor and material and monetary resources.

Within that narrative, it is suggested to improve the Kolos software package, developed at the State University of Land Use Planning, Moscow [9], for the following purposes:

- assessment of various options for organizing crop rotation on the farm, selecting the best;

- assessment of the territory structure for the best version of the crop rotation system;

- assessment of technological production indicators.

The work begins with clarifying the standards necessary for planning agricultural production, taking into account the natural conditions of the economy arrangement and the economic characteristics of its activities. The selection of regulatory and guidance information is currently made for the natural conditions of the Central Federal District for 30 agronomic crops and all types of livestock.

Further, taking into account the proposals $[10,11,12,13]$, actual data on the activities of the agricultural organization is entered into the software package:

- data on the quantity and shift production of agricultural machinery, the area of crop rotation and the number of fields, the area of field roads, the area of crops sown, the content of humus in the soil, the average slope of the area, the distance to crop rotation, the average length of the bout, etc.; 
- economic indicators: labor costs for the cultivation of crops, the cost of organic fertilizers, lime, wages, the cost of operating agricultural machinery, the cost of agricultural products.

Using the actual indicators of the agricultural enterprise will allow to take into account the economic features of its functioning and calculate the amount of net income in actual numbers.

The automated assessment of normative and actual indicators, which takes place in the following blocks of the program tables, allows analyzing up to 10 options for organizing a crop rotation system and arranging their territory. The recommendation for selecting the best option is given by the software package. It is based on the final calculations presented in the summary table where the options for organizing the crop rotation system are evaluated.

In the last block of the program, the technological indicators of the production activities of individual parts and the economy as a whole are calculated according to the recommended option for organizing a crop rotation system, which are the basis for the formation of a business plan for the economy.

Thus, the algorithm for solving the problem consists of the 5 following steps:

1. Clarification of normative indicators.

2. Entering the actual data of the agricultural organization.

3. Organization of crop rotation options.

4. Arrangement of the crop rotation area according to options.

5. Calculation of performance indicators for the recommended option.

\section{Results and discussion}

The implementation effectiveness of the software package was assessed according to the example of the agricultural enterprise AO "Malaya Zemlya" of the Voronezh region. The area of the farm is 2557 ha, land is used intensively, the index of ploughness is $80.8 \%$. The farm is located on the Oka-Don Lowland. The climate is moderately continental with hot and dry summers and moderately cold winters with stable snow cover and well-defined transitional seasons. The annual precipitation in the territory is more than $550 \mathrm{~mm}$. The territory belongs to the zone of insufficient moisture, which is due to a sufficiently high evaporation of moisture in the warm period.

The largest area in the structure of farm lands is occupied by chernozems - 658 ha $(83 \%$ of the farm area). The granulometric composition of soils predominantly consists of heavy loam and clay. There is about $30 \%$ of washed soil in the farm ( $730 \mathrm{ha})$.

AO "Malaya Zemlya" specializes in the production of sugar beets and is a supplier of the Pereleshin sugar factory. The economy has meat and dairy specialization in livestock farming. The on-farm land use planning project involves the future economy specialization in the cultivation of sugar beets with an increase in its area, as well as cultivation of winter grains and herbs (as the best predecessors).

In accordance with both classical recommendations and modern literature, the best predecessor for sugar beets are winter crops, sown in clean or occupied fallow grounds. The highest yield of sugar beets is provided when it saturates the crop rotation by $20-25 \%$ and returns to its former place in 3-4 years.

An important point in the production of sugar beets is the transport factor, since it is necessary to deliver bulk crops to the central collection point of the farm.

Based on the known data in the Kolos software package, a comparison of four development options was made for the territory of an agricultural organization. According to the results characterizing possible crop rotation systems, it was decided to consider in detail only two options, which formed the basis for the organization of arable land. 
Undoubtedly, this allows reducing labor costs for designing at the initial stage.

According to option 1, the development of 2 beet field crop rotation is planned (crop rotation with a long rotation of 8 fields and a more intensive 5-field crop rotation, which is recommended for a flexible response to market changes).
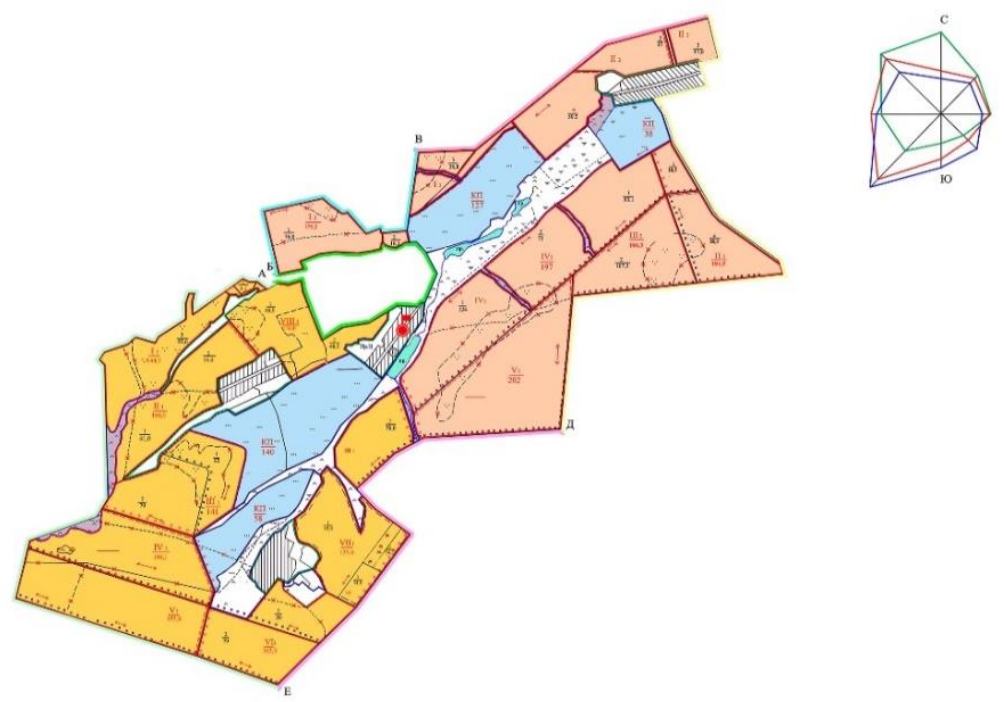

Fig. 1 The project of on-farm land use planning of AO "Malaya Zemlya" of the Voronezh region (option 1)

According to option 2, three 4-field intensive crop rotations are designed, which are more compact, and the average distances to the production center will be shorter.
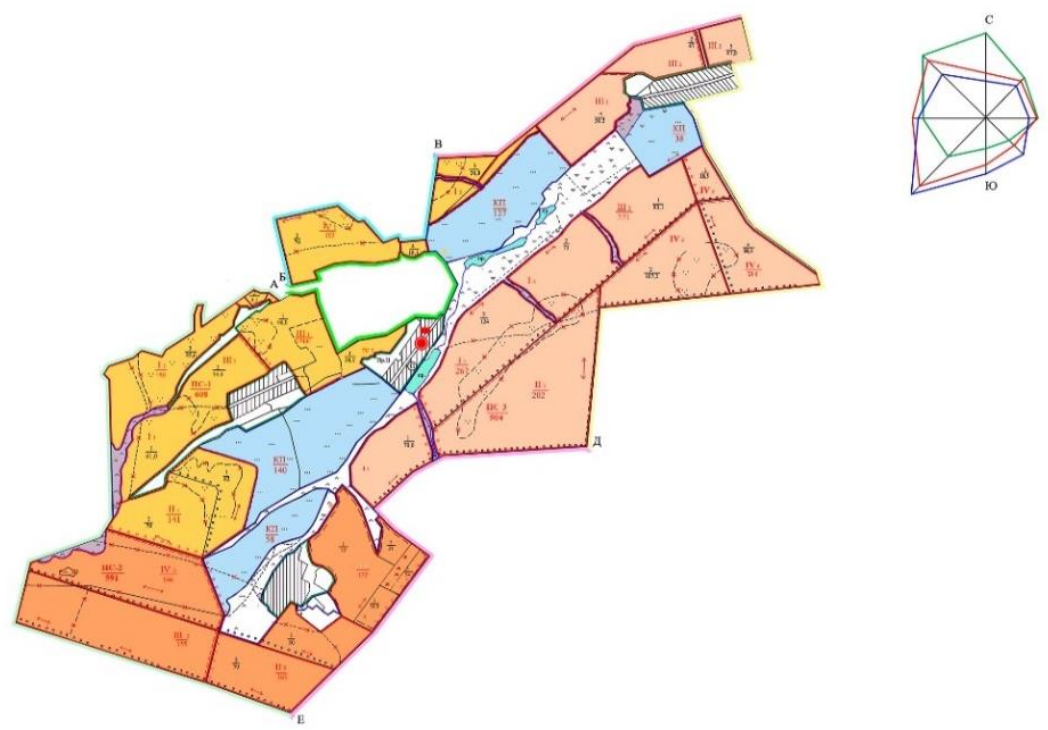

Fig. 2 The project of on-farm land use planning of AO "Malaya Zemlya" of the Voronezh region (option 2) 
After clarifying the regulatory data for the conditions of the Voronezh region and entering the actual data on the agricultural organization AO "Malaya Zemlya" in the Kolos software package, results for a comparative assessment of the options (table 1) were obtained.

Table 1. Evaluation of project options (RUB, in thousands)

\begin{tabular}{|c|c|c|}
\hline Indicators & Option 1 & Option 2 \\
\hline \multicolumn{3}{|c|}{ 1. Organization of crop rotation } \\
\hline $\begin{array}{l}\text { The cost of gross output, taking into account } \\
\text { the quality of soils }\end{array}$ & 617637.69 & 798104.32 \\
\hline Costs for agronomic crops & 655616.43 & 644471.87 \\
\hline Additional costs for maintaining soil fertility & 10070.27 & 23408.12 \\
\hline $\begin{array}{c}\text { Costs of free running of agricultural } \\
\text { machinery }\end{array}$ & 9492.66 & 8996.67 \\
\hline $\begin{array}{l}\text { Production lost due to violation of the field } \\
\text { work terms }\end{array}$ & 3508.32 & 8759.98 \\
\hline \multicolumn{3}{|c|}{ 2. Arrangement of crop rotation territory } \\
\hline $\begin{array}{l}\text { Additional output due to reduced slopes and } \\
\text { soil compaction }\end{array}$ & 2616.57 & 3529.15 \\
\hline Production costs for additional products & 523.31 & 705.83 \\
\hline Loss of net crop income (occupied by roads) & 5831.18 & 4533.33 \\
\hline Reducing costs of field mechanized work & 2723.78 & 2968.73 \\
\hline Net income & -62064.14 & 113726.40 \\
\hline Additional net income & 0.00 & 175790.54 \\
\hline Profitability of production (\%) & 0 & 21 \\
\hline
\end{tabular}

According to the table, 2 options for the organization of arable land were evaluated based on 9 economic indicators. These indicators consider soil quality, steepness of slopes, optimal predecessors for crops, fertility, technical equipment of the economy, transport and time factors.

In accordance with the calculations given in the Kolos software package, the implementation of option 2 is recommended for organizing arable land.

The Kolos software package is designed to automate land use planning calculations for organizing the rational use of agricultural land in the context of the developing the "flexible" crop production and the annually changing agricultural market.

Development includes a program in the form of an executable file, placed on the Internet, consisting of standardized reference data and a calculation algorithm.

\section{Conclusions}

The software package provides calculations for 10 possible options for organizing a crop rotation system for an agricultural organization. This allows reducing the cost of design and survey work by $10-20 \%$, increasing the information saturation of the final documents (more than 25 comparative tables), comprehensively substantiating land management decisions and ensuring a low risk level.

The software package provides calculation of the main indicators necessary for the economic feasibility of arranging the crop rotation:

- the cost of gross crop production, depending on the various arrangement of crop rotation on the farm, taking into account soil quality;

- production costs for the cultivation of crops and their cost, taking into account the various productive and territorial properties of the land;

- the cost of organic fertilizers necessary to maintain a positive balance of humus in the 
soil according to the options for the projected crop rotation system;

- field to field free running costs of agricultural machinery, completion of work, taking into account the preparation time for moving and re-aggregation;

- the cost of additional field crop production, obtained by reducing the time of field work due to an increase in the productivity of agricultural machinery.

Calculation of indicators considered in the economic justification of territory development of crop rotation:

- loss of crop production on the area occupied by roads, headlands, triangles, wedges;

- additional output by reducing slopes in the working areas, soil compaction;

- reducing the cost of mechanized field work by increasing the furrow length, reducing slopes in the work areas, reducing downtime;

- summary indicators for evaluating options for organizing and arranging crop rotation areas.

Thus, the implementation of calculations in the Kolos software package in relation to land use of an agricultural enterprise will allow the following:

- tracing the dynamics of soil fertility;

- establishing production indicators of labour collectives taking into account the quality and location of the land assigned to them;

- justifying the rent for land;

- designing the optimal crop rotation system based on a comprehensively justified structure of sown areas;

- assessing the implementation indicators for the plan of social and economic development for the crop production sectors, taking into account the quality of the land;

- increasing the profit of an agricultural organization (enterprise) by $10-15 \%$ only due to the introduction of organizational, economic and territorial measures.

At the present development level of society, issues of improving the quality of land management projects are of paramount importance in the context of implementing the concept of sustainable development by the world community. Moreover, the provision of enterprises with comprehensively justified, timely drawn up and approved documentation, which ensures the planning and organization of rational use of land resources is also of great importance.

The automated substantiation of multivariate land use planning projects will allow (having one set of initial regulatory and operational data) determining the most effective way for organizing the considered area, based on solving the environmental, social and production problems.

\section{References}

1. E. Zatsepina, O. Sorokina et al., IV International Scientific and Practical Conference 'Anthropogenic Transformation of Geospace: Nature, Economy, Society' (ATG 2019) 321-325 (2020). https://doi.org/10.2991/aer.k.200202.065

2. G. Polunin, V. Alakoz and K. Cherkashin, IOP Conf. Series: Earth and Environmental Science, 274, 012017 (2019) https://doi.org/10.1088/1755-1315/274/1/012017

3. J. Wójcik-Leń, K. Sobolewska-Mikulska et al., Land Use Policy, 78, 36-45, (2018), https://doi.org/10.1016/j.landusepol.2018.06.044.

4. S.I. Nosov, B.E. Bondarev, K.I. Cherkashin, IOP Conference Series: Earth and Environmental Science, 320(1), 012001 (2019). https://doi.org/10.1088/1755$\underline{1315 / 320 / 1 / 012001}$ 
5. L.E. Petrova, O.A. Sorokina et al., IOP Conf. Series: Earth and Environmental Science, 350, 012042 (2019). https://doi.org/10.1088/1755-1315/350/1/012042

6. O.A. Sorokina, L.E. Petrova et al., IOP Conf. Series: Earth and Environmental Science 350, 012070 (2019). https://doi.org/10.1088/1755-1315/350/1/012070

7. V.V. Vershinin, A.A. Murasheva et al., International Journal of Environmental and Science Education. 11(12), 5058-5069 (2016).

8. K.L. Lidin, M.G. Meerovich et al., ESPACIOS, 39(1). 12 (2018).

9. S.N. Volkov, E.V. Cherkashina, D.A. Shapovalov, IOP Conf. Series: Earth and Environmental Science, 350, 012074 (2019) https://doi.org/10.1088/1755-1315/350/1/012074

10. A.J. Ringrose-Voase, G.J. Grealish et al., Geoderma, 352, 299-313 (2019), https://doi.org/10.1016/j.geoderma.2017.10.014.

11. K. Piikki, M. Söderström, Geoderma, 352, 342-350 (2019). https://doi.org/10.1016/j.geoderma.2017.10.049.

12. M. Khorchani, E. Nadal-Romero et al., Science of The Total Environment, 717, 137160 (2020). https://doi.org/10.1016/j.scitotenv.2020.137160.

13. T. Xu, J. Gao, Y. Li, Land Use Policy, 87, 104030 (2019), https://doi.org/10.1016/j.landusepol.2019.104030. 